\title{
ON CIRILO BAUTISTA'S ONTOLOGY OF THE POEM
}

\author{
Noelle Leslie dela Cruz \\ De La Salle University, Philippines
}

\begin{abstract}
In Words and Battlefields: A Theoria on the Poem, Cirilo Bautista advances the thesis that there is such a thing as a Filipino epic and that it is key to nation-building. ${ }^{I}$ Well known for his long-form poetry, Bautista can be said to be taking a position on one of the main issues in the philosophy of poetry, namely the ontology or being of poems. I argue that his theory of the poem has three cornerstones, which I critique and evaluate through a close reading of the epic poem "The Cave."
\end{abstract}

Keywords: Ontology of the poem, philosophy of poetry, Cirilo Bautista, the epic, "The Cave"

\section{INTRODUCTION}

In the nascent area of philosophy of poetry, a subfield of contemporary aesthetics, a key problem concerns the nature of poetical works. ${ }^{2}$ Most critics and philosophers take it for granted that "poetry" refers to written work, typically in the style of the modern lyric, which is comparably short and features a subjectivity that expresses a sentiment. However, this assumption ignores the vast tradition of oral poems, especially before the invention of writing. This variety of forms raises ontological problems such as the following identified by Rubeiro $(2015,130)$ :

How can a single work have so many texts?... Is there a single ontological kind when it comes to poetry, or are there different kinds, depending on the poetic tradition from which the work emerged?.... where, and what, is the poem? To what ontological category does it belong, and what are its properties?.... Should we conceive of its existence rather as a mental event in the mind of its creator? Or should we conceive of it as an event in the minds of readers or listeners?

Bautista takes a position on these ontological issues, which he develops in detail in Words and Battlefields, his critical manifesto. Here, he uses figurative language quite liberally, as well as snippets from various disciplines. The erudite author is conversant with the ideas of diverse thinkers from Adorno to Wittgenstein, applying these indiscriminately over the course of 36 chapters. As the epigraph warns, "This 
discourse on the poem is actually a theory disguised as a parable disguised as history disguised as sociology disguised as a poem. One should be wary of disguises" (Bautista 1998, i). This poses a challenge indeed for anyone who's trying to parse the text for arguments. However, from a careful study of it, one may identify three cornerstones of Bautista's theory of the poem, as follows:

1. The poem is an imagined object, a linguistic disguise of reality, which has the potential to become or supplant reality;

2. The culture and history of a people constitute the essence of a poem; and

3. Thus, poetry is a site of nation-building, which justifies the revival of the epic form in Bautista's own works.

\section{THE RUBBER TOWER}

The first cornerstone of Bautista's theory has to do with the imagination and the process by which it affects reality. The "Rubber Tower," the notion of which bookends the whole essay, is initially defined as "the mind's obligation to perceive as the only reality" (Bautista 1998, 1). Thus, it refers either to the poetic imagination or the imagined poem, possibly both. Bautista $(1998,61)$ preserves the distinction between the imagination and reality: "For the poem is not captured reality, nor reality transformed; it is language pretending to be reality." There is something warlike in this dynamic, as the metaphor of the Tower implies. "The poem was the first emergence in mankind of a verbal disguise to cover man's aggressive nature," continues Bautista. As the verbal disguise of reality, the poem performs the work of transformation that primitive practices such as warfare used to enact upon the world.

Any achievement of consciousness involves struggle or conflict, after all. Thus, the Tower is something to be climbed; its chambers spaces where "torture" may take place. Its connection to the verbal arts is evident in the following passage:

The enemies will come surely, armed with crossbows and javelins and pick-axes and machetes to systematically destroy the Rubber Tower; but in the meantime, the wind hides it, though it is visible to the naked eye. The wind that ruffles the water writes the worm's obituary, all the syllables on the stone that capture and fury and futility of his biography, while the artificial mantle of mourning shakes as if in grief. Only words can scrape the Word growing like a fungus on the tomb. To read the words as they read the Word, as it were, is the central process in grasping the mystery of the Rubber Tower. (Bautista 1998, 5-6)

The creation of meaning through poetry is a siege-like affair, a monumental conquest in comparison to which the poet himself or herself is but a lowly worm. But while the poet's achievements can only be very small and mundane, it is his or her painstaking work that distills the essence of art. The imagery of decay underscores human mortality, which the poem, as a made thing, ultimately transcends. Echoing 
Roland Barthes's famous remarks about the death of the author, Bautista $(1998,80)$ writes,

The poem is a death and a resurrection at the same time. The poet dies into the language which in itself is the death of reality. Insofar as the words are concerned, he is as good as dead when he moves his pen to impress the first letters on the page - the rest merely formalizes his necrological progress. From then on, the poem records itself, that is, it kills the poet's reality by creating a new reality out of his bones.

The "Rubber Tower" is a site of struggle not only in terms of the poet's relationship with his or her craft, but also in terms of the clash of competing views. Bautista $(1998,69,78)$ writes of the "war of poems" which is carried out on "the plane of discourse," and the fact that a poem "can only be wrecked by other poems." Meanwhile, in certain places, the word "poem" shifts in meaning from a verbal work of art to a belief or ideology, as when Bautista $(1998,54)$ compares and contrasts "the poem of religion" (e.g., Islam, Christianity) with "the poem of the world" (e.g., tyranny, democracy) - both of which advocate the slavery of the individual. These ideological clashes can have very real consequences, as when "the poem masquerading as reality becomes reality" (Bautista 1998, 67). This can be seen in the pernicious effects of what he refers to as "the American poem":

The American poem, disguised as a religious poem, and using a benevolent mask, accomplished [American President William] McKinley's objectives with a little blood on the side - a total of 278,232 deaths, 600 million dollars, pestilence, betrayals, assassinations, and family dislocation.

These sinister aspects aside, the successful poem tends to abet social change (Bautista 1998, 90). From the perspective of a repressive regime, the subversive poem is an intolerable rival government (Bautista 1998, 47). Indeed, It can be used in the service of a revolution: "If coercion is the last form of power, revolution is the last form of poetry. Structural antagonisms, terrorized masses, and hungry mobs fill Filipino poems because they fill Filipino streets" (Bautista 1998, 48).

In this way, the poetic imagination plays a crucial role in shaping reality. Thus, it motivates the movement of cultural and national history, which brings us to the second cornerstone of Bautista's theory of the poem.

\section{“THERE COULD ONLY BE FILIPINO POEMS”}

A central thesis of Words and Battlefields is the inextricability of cultural identity from the poem. Any literary classification must be made "in the light of culture, for the poem possesses the energies that reveal its cultural base and direction." 
This entails the rather big claim that "there could only be Filipino poems, Chinese poems, Tibetan poems, etc." (Bautista 1998, 21).

In line with this cultural essentialism, the "textual strategies" of the Filipino poem consist of three idiomatic Tagalog expressions: "Isulat mo sa tubig" ["write it on water"], "pagputi ng uwak" ["when the crow turns white"], and "lantay na ginto" ["pure gold"]. Bautista mines the traditional meanings of these expressions, with their inevitable cultural underpinnings, in order to describe a uniquely Filipino poetics.

The first saying connotes futility, as anything written on water is bound to dissolve. The attitude arising from this observation is a symptom of the colonization and miseducation of the Filipino psyche. Thus, modern Filipino poems tend to express a sense of alienation:

... he wrote on water a book of water, in the attempt to destroy his words even before they came to existence so that they would be eternal. Ho! Ho! And what did he write? His radical debts, the tally of things he never enjoyed, his people's sadness and their joys also, his ritual dreams and dreamy rituals. (Bautista 1998, 8)

The second saying, the full rendition of which is "pagputing uwak, pag-itim ng tagak" ["when the crow turns white, when the egret turns black"], refers to the impossibility of an event ever happening. In this sense, it is comparable to the English idiomatic expression, "when pigs fly." Bautista's interpretation adds another layer to it, such that one may refer to the possibility of impossibility - at least in relation to the endless interplay of meaning in the Filipino poem. While no ultimate meaning may be pinned down in the text, the text paradoxically becomes meaningful precisely because of its continuous hermeneutic evolution. Meaning is impossible, yet possible at the same time. This can only stem from "the Filipino's enormous capacity to dislocate realities by unshackling words from their umbilical cords" (Bautista 1998, 15). For him, "a poem... is not a factuality of text but an ever-recurring re-arrangement of text; in this light also, it must be seen that a poem is never a final poem, for it is in a state of flux" (Bautista 1998, 17).

Lastly, the third saying alludes to the common practice of panning for gold. Just as the process involves the sifting of what is valuable from the sediments, so too must the Filipino poet struggle to articulate a pure message on the basis of the cultural past. Writes Bautista $(1998,10)$,

Did what he say contain what he thought? Did what he think contain what he said? For only in mutual containment can national harmony correspond to national expression, making possible a productive exegesis. At the same time, the textual texture between words - the solid nothinghad to be retrieved and posited against the utterance of the national consciousness to discover thresholds of experiences that remained unexamined. 
Some sifting must also be done in interpreting the text of a nation's history. Along this vein, Bautista $(1998,13)$ presents a brilliant and unusual reading of Philippine history during the long centuries of Spanish rule, drawing a parallel between two deaths: that of Magellan in the 1520s at the hands of the natives, and that of Rizal in the 1890s at the hands of the colonizers:

When the natives killed Magellan, they interrupted the inter-textual congruence of Euro-Asian utterances and interposed a non-literary belligerence; when the Spaniards killed Rizal, they transformed a literary text into a political text, and encouraged a literary belligerence. In both cases, there was textual confrontation. The inability of the people to interpret the absence of text between the two texts - the meanings that are not meanings — caused them to live in more than three centuries of misery.

Thus, the skills of poetic crafting (i.e., writing the past) and critical reading (i.e., interpreting the past) are intertwined. Inasmuch as the Filipino poet is a creature of his or her cultural history, he or she can only produce Filipino poems.

This second aspect of Bautista's theory of the poem is perfectly embodied in The Trilogy of Saint Lazarus. Though the work is too complex for me to do it justice here, it is worth noting that it is the application par excellence of his arguments. The work takes its name from the saint whose feast day it was when the Spaniards first sighted the Philippine archipelago on March 16, 1521 (Bautista 2001, ix). The trilogy includes the following epic poems, each composed of at least 3,000 lines and published separately over the course of almost 30 years: The Archipelago (1970), Telex Moon (1974), and Sunlight on Broken Bones (1998). ${ }^{3}$ Bautista $(2001$, x) summarizes their content thus:

The first book begins with the colonization of the Archipelago and ends with the conviction of Rizal; the second concerns Rizal's exile to Dapitan and ends with his return to Manila; and the third begins with the Philippine revolution and ends with the EDSA upheaval.

From the foregoing, it is evident that the contribution of Bautista's poetry to the articulation of Filipino-ness cannot be underestimated. Poetry and a country's history are intertwined. He believes that "History as a development of the poem, of being, ensures the continuity of national consciousness, builds and maintains its understructure" (Bautista 1998, 31). Indeed, his oeuvre is comparable to that of Homer and Virgil, epic poets who shaped Greek and Italian histories, respectively. Analogously, The Trilogy of Saint Lazarus aims to fill the gaps of Philippine history (Bautista 1998, 95).

\section{BAUTISTA'S REVIVAL OF THE EPIC}

Related to the centrality of culture and history in Bautista's theory of the poem is the third and last cornerstone of it. As his work shows, the epic form is significant 
in the writing and (re-)imagining of a nation. A simple though not unproblematic definition of the epic is "a long heroic and nationalistic poem" (Johns-Putra 2006, 2). This underscores the significance of form in the composition of any national literature. Bautista's revival of the epic entails an advocacy of a structural shift from the visual to the aural, and consequently a stinging polemic against what remains to be the prevalent literary style, i.e., the lyric.

Nowadays, most people understand the term "poetry" to mean the modern lyric, although there are certainly other competing contemporary styles such as language poetry and spoken word poetry. Traditionally defined, the lyric is a "necessarily brief... record of a momentary experience distilled and compressed to reveal feeling and emotion" (Lindley 1990, 188). Although poetry has many different forms, such as the elegy, the epic, and the narrative, at some point in history, the lyric mode became dominant. Modernity and the invention of printing are crucial factors, as poems began to be read and reflected upon silently rather than performed or sung. This development saw a historical shift from a pre-modern preoccupation with the external world to a modern concern with consciousness and subjectivity, as well as a shift from communal concerns toward personal ones (Oppenheimer 1989, 3-12, passim).

When the 27-year-old Bautista burst into the Philippine literary scene with the publication of his first book, The Cave and Other Poems (1968), the writer Nick Joaquin welcomed what he described as "a new manner in Philippine verse: the long line, a more heroic music that departs from the conversational tone so stylish among our young poets, and shy, muted rhymes." He continues,

Bautista is the long-needed break-away from the lyric tradition that [Jose Garcia] Villa created. Our verse has too long tried to be casual and exquisite about God and Me. Our young poets seem to shy away from hard verse. They get stuck in soft statements about themselves smoking a cigarette or drinking beer while pondering a lonely world. .... At his best, Bautista can swing the long line and sustain it on page after page, sustaining both the intricate thought and the music of the intricacy until one becomes, as in Wallace Stevens, the harmonium on which the poet improvises. (Joaquin 1968, 1).

Indeed, in his own writings, Bautista embraces the critical consensus that he represents the antithesis of the older and arguably more internationally renowned Villa. In keeping with the view that culture and history are the lifeblood of the poem, Bautista laments the gradual effacement of aural poems such as folksongs. With the invention of writing, the eye replaced the ear, and the poem stopped being a song, thus initiating "the textual tyranny of singular meaning" (Bautista 1998, 72). Accordingly, he criticizes Villa's works:

Jose Garcia Villa, in adopting a rigid form in his experimental works, denied the implicit relationship between the poem's sound and shape, for he limits his text to the visual appeal. His poems lose much of their auditory power because of this. His aesthetics, as explicated in his theory 
of reversed consonants and comma poems, is an accommodation of typographical versatility, a concession to the printing press. Many of his poems are not meant to be heard, nor to be wielded in the battlefield. They are effeminate and would be at ease in the parlor or boudoir. (Bautista 1998, 73)

In his criticism of what he calls the "printing press poem," Bautista draws from the ideas of Marshall McLuhan. He is very much against the tyranny of print, by which the paper becomes part of the poem and so controls it. The poem must burn the paper, so to speak, or otherwise "install an ear" on it (Bautista 1998, 100). The poem demands spoken words, which, although ephemeral, have always been linked with consciousness and not with any externality. This is because the shape of the poem is the shape of consciousness at the moment of creation. Thus, Bautista condemns poems that are only meant to be seen, for example, "The Grasshopper" by e.e. cummings and "The, Bright, Centipede" by Villa. Once exiled on the page, a poem is never heard again (Bautista 1998, 103-105). He concludes that the poem as a speech act is superior to the poem as a machine act, in that "the poem's oralness harnesses society's collective genius." By comparison, the visual text is a kind of false history (Bautista 1998, 132).

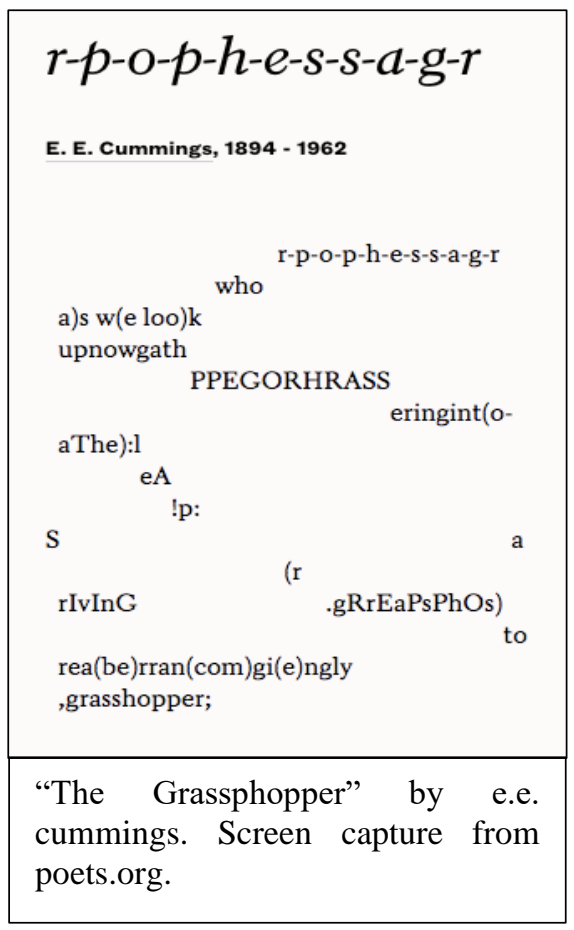

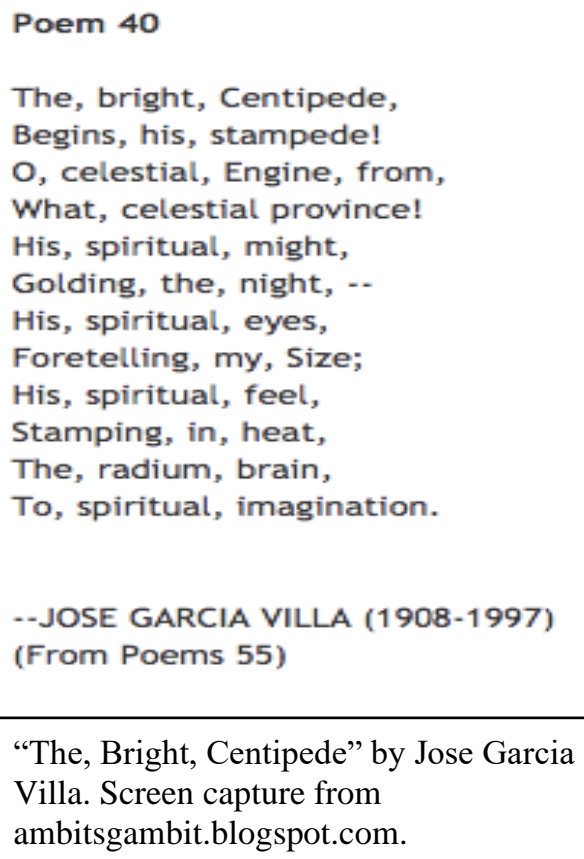

"The, Bright, Centipede" by Jose Garcia Villa. Screen capture from ambitsgambit.blogspot.com. 
One may, of course, argue that even Bautista's long poems are printed works. However, there is a big difference between them and visual poems. Bautista's works are less writerly than bardlike. There is also something essentially declamatory about them. As Demetillo $(1995,217)$ observes of the poet's unique style,

The most characteristic poems of Cirilo Bautista are projected not as lyric songs but as addresses or public speeches; hence, the long lines and the involved syntax. He does not get into intimate revelations in a lowkey or conversational manner with short lines, but he arranges his hexameter iambics in periodic sentences, the poems being best recited in full-throated voice to capture resonance.

Bautista tends to write in the form of the literary epic. According to Beissinger et al. $(1999,7-8)$,

From the perspective of scholars of folklore, literary epic, unlike oral traditional epic, is usually seen as the creation of a single author, immersed in literacy and everything that literacy brings with it. Literary epic is created with artistic perfection in mind, not expediency of performance. It is imagined as an art form crafted by someone with the leisure to chisel phrases, verses, and sentences, to develop and refine artistic expression with the author's best as the desired outcome.

Although the literary epic is a written form, which is inevitable in light of today's reading and writing culture, its breadth, style, and subject matter harken back to those primitive impulses that underpin a people's communal experiences. Bautista's long poems, though they may be enjoyed and appreciated when silently read, can only achieve the full potential of their form when they are recited in public. Their form and content mark his works as literary objects for a people's shared experience, i.e., as performances. In his theory of the poem, Bautista tries to extend this thesis not just to the epic genre but to the entire poetic tradition.

To underscore the revolutionary implications of Bautista's epic revival project, I shall close this section with an analysis of his long poem "The Cave." I single out this piece partly because of its comparably manageable length and partly because I believe it constitutes an elegy for the dying epic consciousness.

"The Cave" is a five-part poem ostensibly about the famous cave paintings and engravings in Lascaux, France. ${ }^{4}$ These are some of the oldest artistic creations, dating back to 20,000 years ago, when anatomically modern humans first emerged (Battaile $1955,27)$. The sections of the poem thematically follow the images in various areas of the cave: the Great Hall of the Bulls, the Painted Gallery, the Lateral Passage, the Main Gallery, and the Shaft of the Dead Man. Bautista uses a number of devices, such as making the animals - i.e., the bulls — speak, constructing narratives from the primitive scenes depicted on the walls, and connecting the images themselves to certain events in history, such as the Spanish conquest of Central America. 

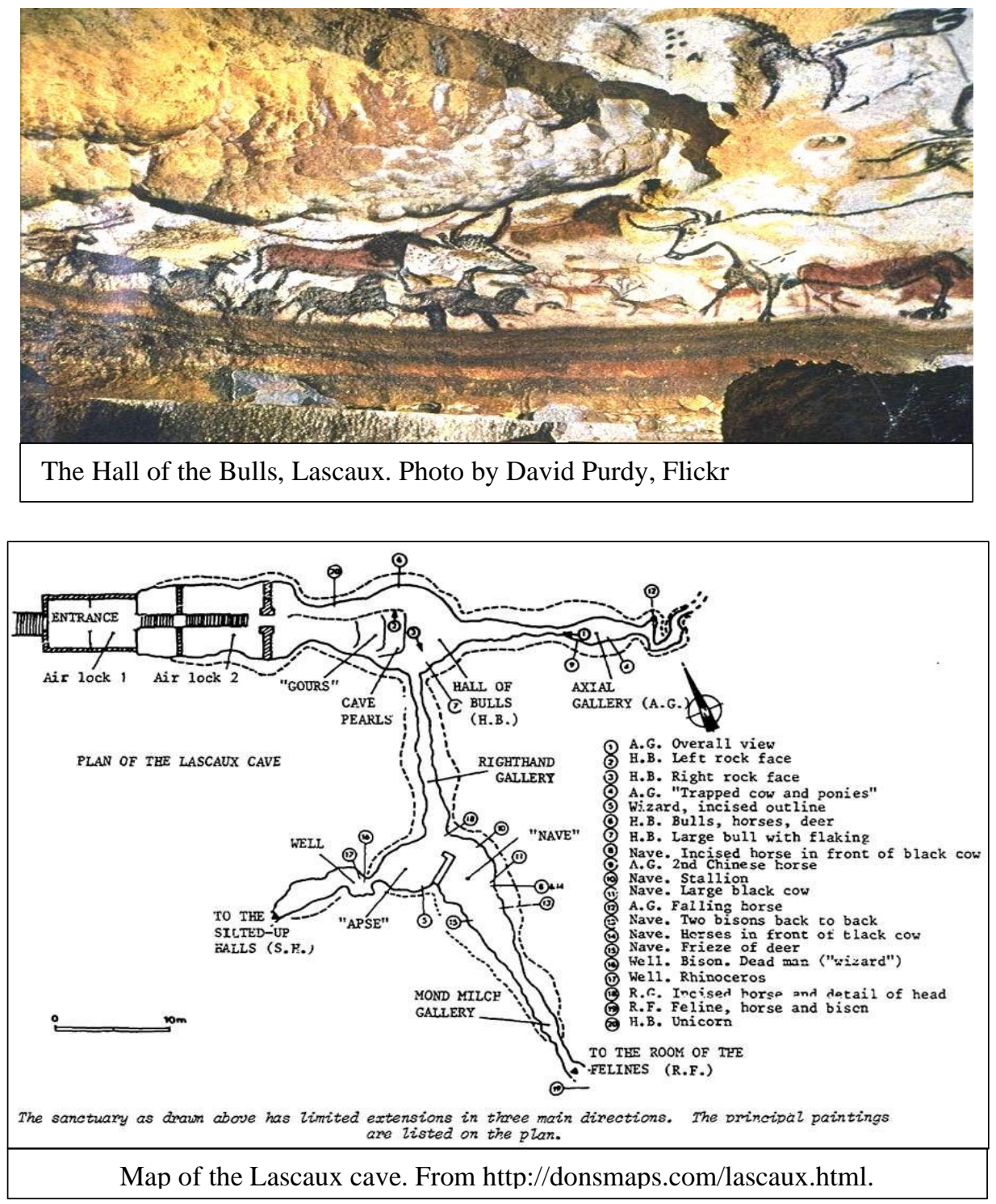

"The Cave" is not easily comprehensible and may require at least two or three readings, or even more, for its full significance to emerge. In this regard, I agree with Canilao's observation that the poem represents Bautista's "reordered reality," which is in keeping with the theory of the imagination presented in Words and Battlefields. Before we proceed with a close reading of the text, it is worthwhile to note what kind of transformation Bautista is trying to effect here, by means of the ancient symbols that resonate throughout human history: 
Lascaux is much more than the cave and its Paleolithic animal paintings and engravings; it includes ideas about it like the speculations, observations of cave art specialists, anthropologists, artists and even tourists. Lascaux is associated with primitive existence, primitive rituals, primitive art, but existence, rituals, art nevertheless, however primitive. These objective realities have been investigated by the poet through his own initiative. For it was Bautista who "went" to Lascaux and its surrounding "outlands." He contemplated these realities; saw them through his "temperament"...; transformed them; transmuted them; reordered them for the reader's pleasurable and profitable contemplation.

(Canilao 1995, 164)

The cave motif features prominently in Western literature, from the myth of Orpheus to Plato's famous allegory. It is also evident in the epic tradition, in which heroes typically embark on an underworld journey (e.g., Odysseus in Homer's The Odyssey, Aeneas in Virgil's The Aeneid, and Dante in The Inferno). These journeys usually facilitate a dialogue with figures from the past and culminate in some form of enlightenment when the hero emerges from the cave. Thus, caves tend to symbolize transition or transformation.

I think Bautista's choice of the Lascaux cave as a setting points to what his poem is centrally about: the epic poet's realization that the oral tradition can never be recovered. Something irrevocable has happened in human history, such that art, as we know it today, bears the mark of loss. Beholding art, we also come face-to-face with the evidence of our own violence - the violence of writing-as-civilization. My reading of "The Cave" echoes Canilao's $(1995,172)$ view that the poem laments a lack of ancestry, but I disagree with his explanation that this has something to do with modern humans' alienation from God or primitive religion. I argue that instead, we are alienated from the oral epic tradition itself. In this way, "The Cave" is a self-referential epic that tolls its own death.

In the first section, the verse that precedes the speech of the four bulls sets up a static tableau, describing how the great animals have been petrified on the walls "Without sound, and soundless too their looks bred/ In perpetual primitiveness...." Vividly depicted, they appear to be alive, but their "brains and hearts [are] pulsing in silence/ Like a wound" (Bautista 1968, 60). Reading these lines in terms of Bautista's aural/visual dichotomy suggests the tragic defeat of heard-words to seen-words. The first bull's declaration that "At the moment/ Of vision one sees nothing" may as well be a description of the emptiness of the so-called printing press poem. It is an abortion of sorts (an "abstraction of the womb, wrought/ In destruction before it was born"). The bull is like the clever experimental poem printed on the page, which has no life beyond the confines of its paper frame. As he says, "I am caged in the brilliance of my greatness" (Bautista 1968, 61).

The speech of the other three bulls has a similar elegiac tone, expressing both sadness and pain. The third bull brings up a recurring reference, which is the Spanish conquest of Mesoamerica and the eventual destruction of the Aztec and Maya cultures. 
These atrocities are to have lasting effects, even for history's victors. It is hinted that famous conquistadors such as Pizzaro, Cortes, and Diaz may be in the same predicament as the bulls: "... like us, [they are] lost in/ Our loneliness, denying roots." The third bull ends his speech with the following lines:

And so, beyond this rock, there is no going,

And if we look back, the skeletons of our age

Will rise in recognition and at once reckless

And defiant will punish us for the betrayal.

By us all is to be had, except beginning. (Bautista 1968, 62)

Thus, the expansion of Western civilization during the age of colonization has meant the annihilation of non-Western cultures, a violent loss from which there can be no recovery. This literal slaughter is dramatized in the second section of the poem, which interprets the images on the cave walls from the point of view of a priest performing a ritual animal sacrifice. Fray Landa, a Spanish bishop responsible for the torture and execution of thousands of Maya people, is given some speaking lines in the third verse, in which he ironically deplores the Mayas' religious practice of human sacrifice (Bautista 1968, 64). Clearly, civilization is a betrayal that deprives modern humans of their connection to their roots. In terms of poetic art-Lascaux, after all, is about the birth of art - the advent of written literature and its mass production in the age of print murdered the oral tradition, as in a ritual killing. The art of the primitives can only be seen now as if in a museum; we can never again enter into their consciousness.

The third section of "The Cave," which references the Lateral Passage adjacent to the Hall of the Bulls, may be read as a statement about poetic form. It describes the uncomfortable confines of the area, concluding that "If 'form follows function,'/ Then the shape of freedom is love,// Then the Passage is not shaped love,/ Nor shaped dream - an error in architecture...." Here is a place where "ecstasies... could not be gotten, though/ Beast and artist crawled on bent knees" (Bautista 1968, 67). Compared to the length and breadth of the epic, the lyric is rather short. Might composing sentimental lyric poems, which may not even exceed a single page, be comparable to being stuck in the Lateral Passage, in which one is loveless and deprived of artistic freedom?

The fourth section continues the meditation on aesthetic form. Limestone, a type of sedimentary rock found in cave systems, is described as "the coward/ Medium." Its use by the prehistoric artists is an "error of the mind" as well as an "error of being." It is through the process of limestone's calcification that these prehistoric images have been preserved at all, but Bautista suggests that preservation is actually perversion. The animals desire to express themselves, but the chosen medium limits them: “... watch the darts numbering/ The bison's bones: his imprisonment is steel/ Pursuing the course of lime. Steel and lime/ Are the frieze of enmity scorning Time" (Bautista 1968, 67). There is a tragedy of artistic failure here, likened to the frustrations experienced by artists as diverse as Dante, Bernini, and Van Gogh, the last having committed suicide. The fault inheres in "How the supreme/ Idea pulled by limestone, 
choked itself/ Fell into the precipice and buried itself/ among these rocks" (Bautista $1968,68)$. The capacity of the medium to stifle the ambitions of art is evident in these lines, which brings us back to Bautista's criticism of the printed word. As he writes in Words and Battlefields, "The paper controls the poem and, by extension, the mind behind the poem" (Bautista 1968, 100). Limestone is to cave art as paper is to modern poetry.

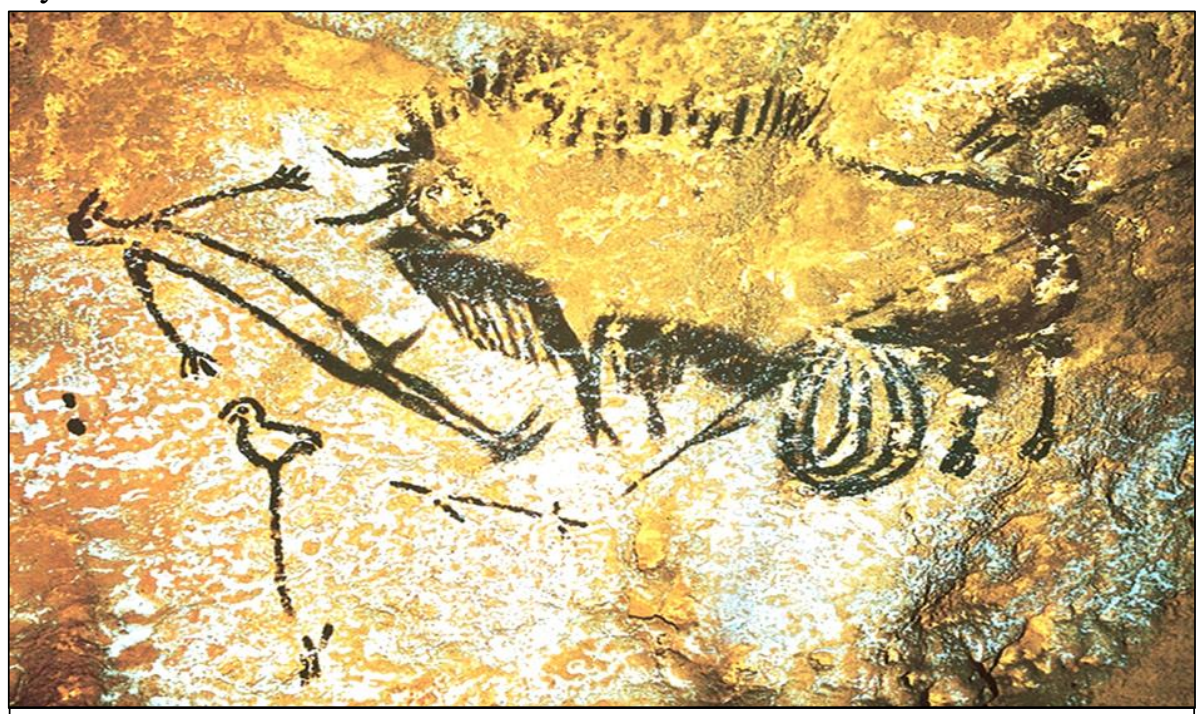

A man with the head of a bird and eight fingers appears to fall prostrate before a wounded bison. From http://www.kenneymencher.com/ 2015/01/is-this-birdheaded-man-is-this-wounded.html.

Finally, the fifth and last section of "The Cave" centers on a rare depiction of a human figure located in a shaft that is 16 feet deep and presently could not be reached without the aid of a ladder. The figure may be read as the artist, whose "ears/ Must catch precious shadows cold in the grave...." (Bautista 1968, 68). Given his birdlike head, he is imagined as a winged creature, having "soared to his sacred imaginings." However, he is now falling into this pit in the heart of the cave, called a "yawning eye." The eye, as the organ of sight, receives images. Metonymically, it is the artist's capacity to discern: "And thus the bright/ Metaphor, blossoming in metallic/ Fierceness, assaults the eye and squeezes a sight...." However, it seems that whatever is received is not translated into a creative object. "The black pool of the eye has sucked/ The image in, drained its content, till its bone/ Lies shining white" (Bautista 1968, 69). Once again, these lines suggest artistic failure. The latter part of the section tells of how at first, the artist has exuded confidence, only to be proven unequal to his artistic task: "He strode in the glory of his vision,/ Thinking, My eight fingers rule this cave...." It turns out that the metaphor is numerically more than he could handle. It is "The metaphor dressed in thunder, thick with lime,/ Its fifty fingers curled around a hammer/ Which drives him to the edge of the eye." His hubris is to be his downfall. 
He plunges into the shaft, at the bottom of which he finally "lies shattered/ ... the metaphor dead in his throat" (Bautista 1968, 70).

As endings go, this last line is a powerful conclusion to a powerful poem. If we pursue the reading of "The Cave" as an elegy for the oral epic tradition, we can interpret the ending as referring to the death of the last bard. The bard's song never gets past his throat. The failure may be due to the enormity of what begs to be expressed (i.e., the "metaphor," a figure of speech that describes one thing in terms of another). However, more likely, it is due to the vices of vision. The shaft the artist falls into is likened to an eye, not a mouth. The mouth is silenced forever. Thus, the visual is the death of the oral/aural.

\section{IS THERE SUCH A THING AS A CONTEMPORARY FILIPINO EPIC?}

Thus far, we can see that Bautista's ontology of the poem treats it as an imagined object that can be translated into reality. Furthermore, it is inextricable from a people's culture and history, and as such, can be a site of nation-building. In this section, I present a critique of these key claims.

Any "contemporary Filipino epic" produced from Bautista's framework is open to criticism in at least two respects. First, we may ask what makes it "Filipino." Second, we may ask whether it has a place and relevance in the contemporary setting.

What makes a Filipino epic? Any claim that involves the referent of the word "Filipino"- such as Bautista's view that there could only be "Filipino poems"invites vexed discussions about the (im-)possibility of national identity. Benedict Anderson's famous analysis of nationhood in terms of an "imagined community" raises skeptical questions about universally shared facts (as opposed to fictional narratives) of experience. ${ }^{5}$ The critic Mikhail Bakhtin has called our attention to the ways in which the epic tends to promote fictions of group identity "bound by linguistic ties (the Homeric epics), tribal bonds (the African poem Sun-Jata), religion (the Pentateuch), nationality (Camões's Lusiades) or empire (Virgil's Aeneid)" (Beissinger et al., 1999, 5). Such fictions tend to erode diversity in favor of an identity that is really based on the experience of a privileged few. For instance, Bautista's notion of the Filipino poem reflects the point of view of a male ilustrado, as revealed by his gendered metaphors as well as his preference for the Christian/Hispanic aspects of Philippine history.

The metaphor of the "Rubber Tower" clearly emerges as a phallic symbol regardless of Bautista's conscious intentions. His view of the poetic imagination skews toward the vertical and the linear-dare we say the logocentric? The imagined poem, which reaches toward the sky, is something to be both scaled and defended. Its achievements take place in the context of combat. Indeed, his criticism of Villa's lyric poems is very telling as "effeminate" and incapable of being wielded on the battlefield (Bautista 1998, 73). These gendered associations are, of course, culturally constructed, and arguably a female poet may adopt these conventions just as easily as a male one. But their masculine connotations are undeniable. ${ }^{6}$

Meanwhile, Bautista's privileging of Hispanic culture and the Christian worldview it brought to our shores can be seen in his favored use of the metaphor of 
transubstantiation in Words and Battlefields. For example, he notes how the (Filipino) poem gained an absolute existence with the consciousness of history, through the literary insurgency of Rizal_ — "and the Flesh was made Word" (Bautista 1998, 28-29). His reading of another Filipino icon, the Catholic priest and rebel Conrado Balweg, repeats this Christian motif, as when Bautista imagines him performing the Eucharist in the wilderness, conflating his person with both the poem and body of Christ (Bautista 1998, 38).

Furthermore, Bautista's epic opus, The Trilogy of Saint Lazarus, ignores our pre-Hispanic heritage. Compare this with the work of Alejandrino Hufana in Poro Point (1961), in which the author "assumes the role of over 150 personae from the Ilocos region," or that of Ricardo Demetillo in his trilogy based on the folk narrative Maragtas, the story of how ten datu groups fled from Brunei and resettled in central Philippines three centuries before the arrival of the Spaniards (Casper 1995, 260). Of course, one may argue that Hispanization is integral to Filipino identity, as the term "Filipino" itself originally referred to Spaniards born in the Philippines during the Spanish colonial era (Wickberg 2001, 49). However, Bautista's decision to begin his epic with Magellan's arrival ignores indigenous narratives which are also part of our culture, no matter how the term "Filipino" may have been derived.

Can there be a Filipino epic in the contemporary setting? Bautista's defense of the epic form as superior to the lyric and as encapsulating a people's culture is poignant indeed. Nonetheless, one must also be wary of the view that the aural/epic mode could or should supplant the visual/lyric mode, especially in light of the digital revolution.

The invention of writing has irrevocably changed our consciousness, and no amount of valorization of the oral tradition can bring back an originary or primitive worldview. The epic in its present-day form has largely become a literate affair, and even epics that predated writing are mostly known to us today in their written form. It is true that in some parts of the world, the oral traditional epic survives, but the associated methods of composition and reception take place in a setting that would appear very foreign indeed to a literate person. We learn from Lord (1960, passim) that the making of oral poetry involves the use of formulaic expressions and repetitive themes or passages. These serve as memory aids for the singer who performs the piece at the same time that he or she constructs it, with a view to gauging the reaction of the audience. Because of the particulars of their composition, oral poems are markedly different from written ones, both in the pleasures they can give and in the contexts in which they can best be appreciated.

Are there contexts that are conducive to the success of the epic today? A vast number of people who have literary interests are inevitably surrounded by visual language. Bautista's preference for the aural over the visual is hard to sustain given the nature of contemporary media, which renders traditional oral performances as the exception rather than the norm. The exigencies of modern life ensure that digital natives have very compressed schedules, a situation mirrored by their favored media. Going to the cinema has largely replaced watching live dramatic performances, and even movies are increasingly being streamed to devices. Long reading, much less long listening, is precluded by the form through which information usually comes in, e.g., social media posts or tweets. Thus, Bautista's elegiac tone in "The Cave" is understandable. It is difficult to imagine how the epic - even in its written or literary 
form - could make a comeback when people barely even have time for shorter lyric pieces.

This is not to say that it is impossible for the contemporary Filipino epic, as Bautista envisions it, to succeed. To be truly relevant, it needs to be more reflective about its own narratives about cultural identity, taking into account such factors as gender, ethnicity, economic class, sexual orientation, religion, etc. Arguably, this suggestion points to a post-nationalistic project, and I think Filipino poetry is capacious enough to accommodate whatever this project may be.

This is also not to say that the aural element has no place or relevance or that there can be no successful revivals of it. The spoken word poetry movement comes to mind, as well as audiobooks, podcasts, video streaming, and even live billboards people can stare at in standstill traffic. The epic can definitely live and thrive in episodic form, having both visual and aural components. True enough, silent reading has its joys, and I like to think that there will always be serious readers of the epic, no matter how few and far between. However, only by adopting today's technologies of broadcast and performance can this glorious poetic form be finally released from the moldering cave.

\section{CONCLUSION}

In sum, Bautista's ontology of the poem has three key aspects, which pertain to (1) how the imagination interacts with reality, as symbolized by the "Rubber Tower"; (2) the central role of culture and history in the construction of the (Filipino) poem; and (3) the superiority of the aural over the visual, or the epic over the lyric mode. Bautista's ideas constitute a viable position on the question of the nature or being of a poem. In this sense, he is clearly a philosopher both through his critical manifesto in Words and Battlefields and through his poetic works, which embody his ontological theory.

\section{NOTES}

1. Gripaldo (2009) includes this text among a compendium of works of Filipino philosophy. See "The Ideal Poem as the Rubber Tower: A Hermeneutical Analysis of Cirilo Bautista's Theory on the Poem" by Rolando Gripaldo, in Filipino Philosophy: Traditional Approach Part 1, Section 2 (Quezon City, Philippines: C \& E Publishing, 2009).

2. For a comprehensive account of the development of this field, see John Gibson's introduction in the anthology he edited, The Philosophy of Poetry (Oxford: Oxford University Press, 2015).

3. Describing his artistic process, Bautista (1998, ix) writes, "In a manner of speaking, from 1963 to 1998, I wrote only one poem, event though I wrote many poems and published seven books of poetry. This was so because every line I made found its way to a larger corpus of lines; every poem I made joined the stream of poems that eventually formed the ocean of an epic. This was the result of a decision I had made earlier." 
4. Canilao $(1995,187)$ notes that Bautista's source of information about Lascaux was Annette Laming's 1959 book, Lascaux Paintings and Engravings.

5. See Imagined Communities: Reflections on the Origin and Spread of Nationalism by Benedict Anderson (London and New York City: Verso, 2016).

6. While it is not our main subject matter here, it is useful to look into the genre of the female epic as a corrective to the masculinist tradition. Jeremy Downes in The Female Homer: An Exploration of Women's Epic Poetry (Delaware: University of Delaware Press, 2010) provides an in-depth study of epics authored by women. Some famous female epics include The Descent of Inanna by the Sumerian high priestess Enheduanna, Telemachus by Anna Seward, Psyche by Mary Tighe, Aurora Leigh by Elizabeth Barrett Browning, Helen in Egypt by H.D., The Journals of Susanna Moodie by Margaret Atwood, and Annie Allen by Gwendolyn Brooks. Meanwhile, a local work that stands out is Merlinda Bobis's Cantata of the Warrior Woman Daragang Magayon: An Epic (Manila: Babaylan Women's Publishing Collective, 1993), a retelling of the legend of the Bicolana princess from whose tomb the Mayon Volcano is said to have sprung. Also noteworthy is the Aliguyon, an oral epic or hudhud which is traditionally sung by Ifugao women (Mariano 1984, 11).

\section{REFERENCES}

Bautista, Cirilo. 1968. The Cave. The Cave and other poems. Baguio City, Philippines: Ato Bookshop.

Bautista, Cirilo. 1998. Words and battlefields: A theoria on the poem. Manila: De La Salle University Press, Inc.

Bautista, Cirilo. 2001. The trilogy of Saint Lazarus. Manila: De La Salle University Press, Inc.

Bataille, Georges. 1955. Prehistoric painting: Lascaux or the birth of art. Paris: Skira. Beissinger, Margaret, Jane Tylus, and Susanne Wofford. 1999. Introduction. In Epic traditions in the contemporary world. Edited by Margaret Beissinger, Jane Tylus, and Susanne Wofford. Berkeley, Los Angeles, and London: University of California Press.

Canilao, Carlos M. 1995. The Reordered Reality. In Reading Cirilo F. Bautista. Edited by Isagani R. Cruz and David Jonathan Y. Bayot. Manila: De La Salle University Press, Inc.

Casper, Leonard. 1995. Search for the Final Syllable: Cirilo Bautista. In Reading Cirilo F. Bautista. Edited by Isagani R. Cruz and David Jonathan Y. Bayot. Manila: De La Salle University Press, Inc.

Demetillo, Ricaredo. 1995. Cirilo Bautista: Peacocks and minotaurs. In Reading Cirilo F. Bautista. Edited by Isagani R. Cruz and David Jonathan Y. Bayot. Manila: De La Salle University Press, Inc.

Joaquin, Nick. 1968. Introduction. In The Cave and other poems by Cirilo Bautista. Baguio City, Philippines: Ato Bookshop.

Johns-Putra, Adeline. 2006. The history of the epic. Hampshire and New York: Palgrave Macmillian. 
Lindley, David. 1990. Chapter 12: Lyric. In Encyclopedia of Literature \& Criticism. Taylor \& Francis Ltd / Books, 1990. Literary Reference Center, EBSCOhost. 188-198. Accessed July 18, 2018. doi.org/10.4324/9780203403624.

Lord, Albert B. 1960. The singer of tales. Massachusetts: Harvard University Press.

Mariano, Josefina. 1984. Introduction: Aliguyon. In An anthology of ASEAN Literatures: epics of the Philippines. Edited by Jovita Ventura Castro et al. Manila: Nalandangan Inc.

Oppenheimer, Paul. 1989. Birth of the Modern mind. Cary, US: Oxford University Press (US). ProQuest ebrary. Accessed May 16, 2016.

Ribeiro, Anna Christina Soy. 2015. The spoken and the written: An ontology of poems. In The philosophy of poetry. Edited by John Gibson. Oxford: Oxford University Press. 127-128.

Wickberg, Edgar. 2001. The Chinese mestizo in Philippine history. With Chinese trans. by Go Bon Juan. Makati City, Philippines: Kaisa Para Sa Kaunlaran, Inc. 